\title{
C.P. Snow and the Two Cultures, 60 Years Later
}

\author{
W A LTER E. MASSEY \\ School of the Art Institute of Chicago, 36 S. Wabash Ave. Chicago, IL 60603, \\ USA. Email: wmassey@saic.edu
}

\begin{abstract}
This article considers the modern-day relevance of C.P. Snow's 'The Two Cultures' while the author, Walter Massey, reflects upon his own personal journey through these two worlds, from his early life as a student of physics, to his current role as Chancellor of the School of the Art Institute of Chicago. The divisions between the sciences and the arts have been improved over time, thanks to the evolution of both disciplines, the rise of interdisciplinary scholarship, and a more collaborative mindset among scholars of both worlds. Certain shared challenges remain, such as the decline in the perceived value of intellectualism and scholarship among certain segments of society. The keys to overcoming these new two cultures are open communication and transparency.
\end{abstract}

\section{Introduction}

On rereading C.P. Snow's seminal and enduring work, ${ }^{1}$ I was struck by how familiar it was, and yet in many ways how outdated it is. This is not surprising given that the work is almost 60 years old. I had just finished undergraduate school when Snow delivered the Rede Lecture on the Two Cultures and the Scientific Revolution. Given how rapidly science and technology have changed over this period, it is a tribute to Snow's insights that the lecture is still capable of inspiring and provoking discussions and, indeed, arguments.

The Two Cultures of which Snow spoke were at the time a very specific group. Snow states, 'I believe the intellectual life of the whole of western society is increasingly being split into two groups' (Ref. 1, emphasis added). Snow was addressing the highly educated classes, people who were quite knowledgeable, successful and sophisticated in their own fields of endeavour, but lacking in knowledge, or as he asserted, even having an interest in other very important areas. He speaks of humanists who are unfamiliar with even basic scientific principles (the second law of thermodynamics), and who have neither an understanding of, or interest in, how science works. He describes scientists (engineers are mentioned also) who are so 
deeply embedded in their research that they are equally ignorant of the humanities. Snow doesn't really use the term 'humanities', he speaks mostly of writers and those in 'literature', and it is not clear where he places the visual arts. At times he uses the term 'the arts' seemingly to include everything that we would now refer to as humanities. As Frank A.J.L. James notes, 'Snow and [F.R.] Leavis appear to have shared one assumption, namely the belief that literature and culture were the same thing. Snow hardly ever expresses any interest in the visual arts, music, or architecture., ${ }^{2}$

\section{My Personal Journey}

Even prior to reading Snow, I had broad interests beyond physics. In fact, I have always thought that if I had not studied physics I would have liked to become a historian. My curiosity about and eagerness to learn non-science topics can be traced to my undergraduate years at Morehouse College, where as a teenager from the tenth grade of Royal Street school in Hattiesburg Mississippi, I was introduced to a liberal arts education with courses in areas that were fascinating, new and exciting to me. I learned that not all religions were Christian (or even Baptist), and became immersed in art and music appreciation, classical literature and philosophy, and especially history, even as I pursued math and physics.

When I first read Snow's lecture I was in graduate school (in the 1960s) in physics, and was just developing my own intellectual interests within and outside physics. The 1960s were a time of great social ferment - the Vietnam War, the civil rights movement, the Kennedy and King assassinations - so it was very difficult not to be interested in and drawn to social and political issues, and to read and study nonphysics works and non-science literature.

Washington University, where I attended graduate school, was a hotbed of social activism among scientists. Barry Commoner, the founder of Environment magazine, one of the first of its kind, was a professor in biology and helped organize one of the first 'teach-ins' on a college campus to oppose the war in Vietnam. Edward Condon, chairman of the Department of Physics, had been director of the National Bureau of Standards (now NIST) where he was the target of the House Un-American Activities Committee (HUAC) during the McCarthy period. The national physics community engaged in a highly publicized and ultimately unsuccessful effort to prevent his security clearance from being revoked. I took quantum mechanics from Professor Condon, and in class he talked almost as much about the war in Vietnam (he was adamantly opposed) as he did about quantum principles.

We read broadly as graduate students: Kerouac, Ferlinghetti, Joseph Heller, Baldwin, and of course, Vonnegut. However, I do recall an episode which would have brought a smile (or a grimace) to Snow's face. A group of us graduate students wanted to buy one of our most distinguished faculty members, Professor Henry Primakoff, a birthday present. We agreed on a set of the 'Great Books', but one junior faculty member was adamantly opposed, saying 'Professor Primakoff doesn't have time to read things like that, he just wants to read physics'. However, he was a lone 
voice, and Professor Primakoff very much appreciated the gift. I am also sure he read the books. ${ }^{3}$

Washington University, in addition to providing a fertile ground for engaging in social and political issues, was a culturally rich community. It was there I attended my first opera (Così Fan Tutte), and learned to love symphonies and theatre. So, at that time, I interpreted Snow's work through the lens of a budding scientist who had broad interests but was still developing humanist/cultural sensibilities. It was at Brown University, where in addition to being professor of physics I was Dean of the College, that I became more deeply engaged in readings, conversations, and dialogues with colleagues in the humanities, arts and social sciences. This was part of my job as Dean and I loved it.

Having, through an improbable set of circumstances, spent the last seven years as president and chancellor of a major school of art and design - the School of the Art Institute of Chicago (SAIC) - I have acquired an additional lens through which I interpret Snow's work for contemporary times. Now I read the work through lenses shaped and polished over a lifetime (almost) of experiences across multifaceted areas and arenas.

\section{The Two Cultures Today}

If I were writing today about the Two Cultures (and I guess I am) I would not describe them as scientists versus humanists as Snow depicts. ${ }^{4}$ In fact, at least in my experience, within the 'highly educated intellectual community' that I know, there is quite a lively and healthy interest in science by humanists, and vice versa. Snow seems to gauge the interest of scientists in the humanities on the basis of the books they read and/or the authors with whom they were familiar: T.S. Eliot, Ezra Pound, W.B. Yeats, and C.S. Lewis. Most scientists I know would certainly be familiar with and maybe even deeply knowledgeable of writers of comparable reputations in the late twentieth and early twenty-first century: Toni Morrison, David Matthews, Cormac McCarthy, and Joyce Carol Oates, just to mention a few. And those in the humanities are almost certainly curious about, and have some lay-level knowledge of black holes, dark matter, DNA, and gravitational waves (maybe even the Second Law of Thermodynamics).

Snow speaks of dinner conversations where dialogue is difficult simply because the 'two cultures' have nothing in common to talk about across their disciplines. I think this set of circumstances has evolved considerably since Snow's lecture. At dinner parties I attend now, discussions among scientists, humanists, artists and others are quite lively, and even argumentative, engaging in topics that cut across disciplinary lines.

I would suggest that, in general, if Snow were to resurface today he would be pleased at the progress that has been made in bridging the two cultures. Although there are still gaps to be closed, and new divides have emerged that I suspect would not please him. 
In my opinion, there are a number of reasons why the culture gap as described in Snow's paper has narrowed over these past 60 years. In particular, there has been a substantial increase in interdisciplinarity within science, which I think makes scientists more willing and capable of studying across other areas. One reflection of this growth in interdisciplinary research is the kinds of projects funded by the National Science Foundation (NSF). When I was director of the NSF in the early 1990s, the primary mode of funding was through grants to individual principal investigators or PIs. Now it is quite common to have grants go to teams of researchers or to centres and institutes that bring together researchers from multiple disciplines. ${ }^{5}$

Also humanists have become more sophisticated in their use of technology. Information technology and computer usage within the humanities means that scientists and humanists now use common tools and share a common language. The National Endowment for The Humanities (NEH) has an Office of Digital Humanities which funds projects such as the one at Johnson C. Smith University, to create the 'content to populate a digital interactive map of a 150-year-old African American neighborhood in Charlotte, North Carolina that is undergoing significant gentrification ${ }^{6}{ }^{6}$ The methodologies used here would be familiar to a large segment of the scientific community.

Science has also become much more accessible to general audiences, including scholars in the humanities. There have been dramatic increases in science writing in the popular media, science shows on television as well as access to science stories on the internet. It is simply much easier than it was in the 1950s for interested individuals to learn about different fields. In addition, more scientists are writing about science for non-scientific audiences, and hosting TV shows or blogging. Brian Green, Stephen Hawking, Lisa Randall and Carlo Rovelli are just a few whose books have become 'bestsellers'. Neil deGrasse Tyson's recent Cosmos: A Space Odyssey was one of the most watched shows on television. And even non-science shows such as The Big Bang Theory expose audiences to the world of scientists, often in a light-hearted manner.

One of the most significant changes since Snow's era, and one that may prove most enduring, is that Universities and Colleges have been actively engaged in establishing formal programmes to bring scientists, humanists, and artists together in serious collaborative research and teaching efforts. For example, the University of Chicago has established an Arts, Science and Culture Initiative, and Stanford University has similar programmes including one called Art of Neuroscience. ${ }^{7,8}$ My own institution, the School of The Art Institute of Chicago (SAIC) has a collaboration with Northwestern University's McCormick School of Engineering on Data Visualization. ${ }^{9}$ The inclusion of the visual arts in these programmes would perhaps surprise Snow.

As I said earlier, Snow doesn't really address directly the place of the visual arts in the two cultures. He does make a brief reference to the less than salutary role the 'arts' played in influencing sociopolitical movements after the First World War, noting a connection 'between some kinds of early 20th-century art and the most imbecile expressions of anti-social feeling' (Ref. 1, p. 8). The art-science connection is now much more visible and pervasive than in Snow's period. One only has to Google 'Art- 
Science' to appreciate the number of programmes and initiatives that exist at colleges and universities, although they differ in kind and intent. Some are merely projects where artists depict scientific data and experiments in interesting, sometimes captivating and visually compelling images. Often these images can be helpful in revealing patterns in data that may not be easily discerned in other ways.

However, more interesting art-science collaborations aim to discover new insights that will not have been revealed by the artist or the scientist working alone. As Mario Livio says:

I think the main connection (between artists and scientists) at least in my mind is that scientists look at the universe around them, and on one hand they are in awe of it and on the other hand they are puzzled as to how it came to be. So they try to understand it and explain the phenomena that they observe.

Artists also are in awe of the universe around them, but they don't necessarily try to understand how it works; they try to give their emotional response to what they see. In some sense, the scientists and the artists are both responding to the universe, but they respond in complementary ways. ${ }^{10}$

By working together 'in complementary ways' scientists and artists can and have produced fascinating results. One particular project in this regard is 'The Fabric of the Universe', an arts and science collaboration undertaken by textile specialist Isaac Facio (SAIC) and astrophysicist Benedikt Diemer (University of Chicago). The project focuses 'on simulations of the cosmic web of dark matter. However, we aim to go beyond two-dimensional visualizations, and are exploring new ways to represent data using unconventional materials and techniques such as three-dimensional woven textiles.' 11

In 2011 we started a program at SAIC entitled 'Conversations on Art and Science: Is There a There There?" ${ }^{12}$ The question explored in this series is: 'do artists and scientists have commonalities in the way they engage in the creative process, and if so what are they?' We presumed a positive answer to this question; however, the goal of the series is not intended to reach conclusions, but to provoke stimulating exchanges among artists, scientists, humanists and social scientists. It has been successful in that regard. A comment by writer, actor and performer Anna Deavere Smith captures the spirit of the conversations. She says: 'art puts us in an intimate relationship with doubt'. ${ }^{13}$ This is surely what science is all about, dealing with doubt.

These are all positive trends. However, as I noted earlier, there are some developments that I think would not please Snow. In some particular areas of the humanities, scholars are not only interested in and curious about science, but in fact have adopted as an area of scholarly inquiry the study of the methodologies and principles of science. I refer to the group of scholars generally called 'Postmodernists'. The postmodernists (PM) argue that science has no special claim on interpreting 'reality', and that so-called methodologies of objectivity, rationality and reproducibility are social constructions that scientists use to justify the privileged place of science in society. They, the PMs, argue that science is just one of many equally valid ways of interpreting, understanding, and explaining physical phenomena and human behaviour. ${ }^{14}$ 
The 'fake' article by Alan Sokal published in the journal Social Text in 1996 parodied these views and provoked a heated discussion between many prominent scientists (Steven Weinberg in particular) and members of the postmodernist community. ${ }^{15}$

This group of humanists are certainly not disengaged from science, but do constitute a different culture from the scientific community. This cultural divide in my opinion is much more serious and corrosive than what Snow described, because it cannot be bridged simply by having the two groups learn more about each other's areas.

The PMs are just one segment of the larger humanities community (and may be fading), and have not had a serious impact on science itself, but may have provided intellectual support and ammunition for a larger group which, to me, does constitute a different culture that is antithetical to science in a much more serious way, as I explain below.

\section{What Next?}

As I have argued, I believe the particular problem Snow so eloquently raised, i.e. the barrier between scientists and humanists in western intellectual society, has become much less severe. The present-day challenge to both the sciences and the humanities comes from outside these communities. In some ways the challenges are different for the two communities but have somewhat similar origins, which have to do with the declining value given to intellectualism and scholarship among segments of American society.

The humanities, in concrete and visible ways, are much more challenged in this regard. The humanities are increasingly seen by many to be irrelevant to, and impractical for, society. This is problematic at a time when society is more focused on relevant and practical ends. Perhaps as a consequence, the number of humanities majors in colleges and universities has been declining significantly, along with declining financial support for faculty scholarship and research.

The sciences still attract top-flight students and financial support is not declining, yet. The challenge for the sciences is that vocal and potentially influential segments of American society have chosen not to believe that science offers the best explanation of how the universe works, and how to interpret physical phenomena. For various reasons, some cultural, some economic, and some due to lack of exposure, they are sceptical of scientific findings and predictions. Among these groups are the creationists, who doubt evolution; vaccine phobists, who dismiss an established history of scientific and medical findings; and perhaps the most difficult, those who refuse to accept evidence of global climate change and human culpability for these changes. Far from being fringe groups that can be ignored, these groups are now becoming more politically and economically powerful. The PM's 'scholarly' representation of science is certainly not helpful in dealing with these groups. 
The important question for today, I suggest, is how the scientific and humanistic communities, along with our colleagues in the arts and social sciences, work together to address these challenges.

Here, I think we can draw upon and broaden Snow's proposed solution to the problem he addressed, and that is to focus on education. But I mean 'education' broadly defined, not just within academic institutions, but 'education' for the general public. How do we effectively engage these doubting communities to convince them of the importance of the humanities and the validity of science?

There are two very important recent studies/reports that offer helpful advice in this regard. The report titled 'The Heart of the Matter' by the American Academy of Arts and Sciences, issued in 2013, made the argument that, 'the humanities and social sciences provide intellectual framework and context for understanding and thriving in a changing world. When we engage with these subjects, we learn not only what but why. ${ }^{16}$

The National Academy of Sciences also recently issued a report, 'Communicating Science Effectively', on how to improve communication with non-science audiences. The report notes that: 'Communicating about science effectively with public audiences ... turns out to be more difficult than it might first appear,' especially 'when the issue being discussed involves either a domain in which the societal implications of the science are controversial or substantial disagreement about the findings exists within the scientific community. ${ }^{17}$

Both reports make recommendations on how to improve communications with public audiences and on improving science and humanities education, formal and informal.

The NAS in particular recommends an extensive research agenda, noting in the press release for the report:

A major research effort is needed to understand the complex factors that affect science communication - for example, the ways people process the scientific information they hear, and the individual and social factors that influence people's trust in science and sources of information about it. ${ }^{18}$

These recommendations are very valuable and if implemented can go a long way in addressing the challenge our communities face.

With respect to the science community in particular, I would urge a little more 'humility' when speaking about science to non-science audiences. Too often when explaining science there is a tendency to convey scientific findings as more certain, definite and final than they are. The focus of communications skews toward the 'results' of scientific investigations rather than the 'process' of determining these results and findings. I would urge us to speak and write more about how the scientific process works; how and why scientists arrive at particular conclusions.

This is not a 'cure all' of course, but it might help us engage some of our sceptical critics in discussions, and even arguments, about why we have reached certain conclusions and not simply debate whether the conclusions are right or wrong. The audiences who are motivated by economic and political agendas are not likely to 
change their views and behaviours as a result of this approach. However, I think those who are genuinely confused and uncertain about scientific results and predictions (and I suspect there are many in this camp) could have their views affected in a positive manner.

The scientist and educator Cecily Cannan Selby has also urged that scientists revise the way they speak about science for lay audiences, writing (emphasis in original):

I believe that the public discourse about science has been missing a vital message that, if understood and promoted, could profoundly improve student, adult, and societal engagement with science: Aesthetic and humanistic, as well as scientific, perspectives can legitimately influence the choices made in a scientific inquiry.

She goes on to note, 'Unfortunately, public perceptions of science too often thwart this message', and quoting physicist and historian Gerald Holton, 'misperceptions of science can arise because the scientist's "private process of creation" is largely shielded from public view. Only the "public process of validation" is reported in professional journals and monographs. 19

I think, along with Dr Selby and Professor Holton, that if we scientists talk more openly about the 'private process of creation' and the 'aesthetic and humanistic' perspectives that influence our work and not simply the conclusions we reach, we might be able to begin bridging the gap between the new Two Cultures.

\section{References}

1. C.P. Snow (1961) The two cultures and the scientific revolution The Rede Lecture 1959 (New York: Cambridge University Press).

2. F.A.J.L. James (2016) Introduction: Some significances of the two cultures debate. Interdisciplinary Science Reviews, 41(2/3), pp. 107-117.

3. I may be mistaken as to whether the gift was the Great Books, but it was something similar.

4. When I say 'humanists', I am referring to scholars of the humanities, rather than adherents to 'humanism'.

5. For more information, see the National Science Foundation's page on interdisciplinary research: https://www.nsf.gov/od/oia/additional_resources/ interdisciplinary_research/

6. National Endowment for the Humanities, Office of Digital Humanities (2017) Announcing New 2017 ODH Grant Awards. https://www.neh.gov/divisions/ odh/grant-news/announcing-new-2017-odh-grant-awards/

7. University of Chicago Arts (2017) Arts, Science + Culture Initiative. https://arts. uchicago.edu/arts-science-culture-initiative/

8. Stanford University Neurosciences Institute (2017) Art of Neuroscience. https:// neuroscience.stanford.edu/research/programs/art-neuroscience/

9. School of the Art Institute of Chicago (2016) Data Viz Collaborative. http:// www.saic.edu/academics/areasofstudy/artandscience/datavizcollaborative/

10. A. Summer (2016) Astrophysicist Mario Livio on the intersection of art and science. Smithsonian Magazine, http://www.smithsonianmag.com/science-nature/ astrophysicist-mario-livio-intersection-art-and-science-180960334/\#pB1pWd3QZ QuICgtm.99/ 
11. I. Facio and B. Diemer (2017) The fabric of the universe. http://www. fabricoftheuniverse.org/

12. School of the Art Institute of Chicago (2018) Conversations on art and science event series. http://www.saic.edu/academics/areasofstudy/artandscience/conver sationsonartandscienceseries/

13. Anna Deavere Smith, comments at private conference, September 2017.

14. For more background on the Science Wars, see G. Henriques (2012) Revisiting the science wars. Psychology Today, 1 June, 2012, https://www.psychologytoday. com/blog/theory-knowledge/201206/revisiting-the-science-wars/

15. A.D. Sokal (1996) Transgressing the boundaries: Towards a transformative hermeneutics of quantum gravity. Social Text, 46/47, pp. 217-252.

16. Commission on the Humanities and Social Sciences, and American Academy of Arts and Sciences (2013) The Heart of the Matter (Cambridge, MA: American Academy of Arts \& Sciences)). https://www.amacad.org/content/publications/ publication. aspx?d=21724/

17. National Academies of Sciences, Engineering, and Medicine (2017) Communicating Science Effectively: A Research Agenda (Washington, DC: The National Academies Press). https://www.nap.edu/catalog/23674/communicating-scienceeffectively-a-research-agenda/

18. National Academies of Sciences, Engineering, and Medicine (2016) New report recommends research agenda for effective science communication. Press Release, issued 13 December 2016. http://www8.nationalacademies.org/onpinews/news item.aspx?RecordID $=23674$ /

19. C.C. Selby (2006) The missing person in science. Update, New York Academy of Sciences Magazine, May/June, pp. 10-13. https://www.researchgate.net/publica tion/256374377_The_Missing_Person_in_Science_-_Inquiry_Starts_with_I/

\section{About the Author}

Walter Massey is Chancellor of the School of the Art Institute of Chicago, and Chairman of the Giant Magellan Telescope Organization, which guides the construction of the world's largest optical telescope. Massey began his career as a physicist at leading research universities before his appointment as Director of Argonne National Laboratory, and then as Director of the National Science Foundation under President George H.W. Bush. In 1995, he returned to his alma mater, Morehouse College, where he was President for more than a decade. He is the former Director of the McDonald's Corporation, the former Chairman of Bank of America, and has served on the boards of numerous non-profit organizations, including the Mellon Foundation, the MacArthur Foundation, and the Smithsonian Institution. He has honorary degrees from 41 universities, including Yale, Harvard, Northwestern, Columbia, and Brown. 